\title{
Effect of Environmental Temperature at the Milky Stage on Amylose Content and Fine Structure of Amylopectin of Waxy and Nonwaxy Endosperm Starches of Rice (Oryza sativa L.)
}

\author{
Masako Asaoka, Kazutoshi OKuno*,† \\ and Hidetsugu FuwA ${ }^{\dagger \dagger}$ \\ Department of Food and Nutrition, Osaka City University, \\ 138-3-3 Sugimoto, Sumiyoshi-ku, Osaka 558, Japan \\ *Division of Genetics, National Institute of Agricultural Sciences, \\ MAFF, Yatabe, Tsukuba, Ibaraki 305, Japan
}

Received June 18, 1984

\begin{abstract}
Starch granules were isolated from polished grains of rice plants (Oryza sativa L.), waxy and nonwaxy near-isogenic lines of a Japonica rice cultivar, Taichung 65 , grown under controlled temperature conditions. Amylose contents and distributions of $\alpha-1,4$ chains of amylopectin, and further details of the fine structure of waxy amylopectin were determined by enzymatic and chromatographic methods. The higher environmental temperature decreased amylose contents in endosperm starches of nonwaxy rice plants. Moreover, the higher environmental temperature increased the amount of long B chains of amylopectin and decreased mainly that of short B chains and slightly that of A chains as compared with the lower environmental temperature.
\end{abstract}

In the previous paper, ${ }^{1)}$ we showed that rice plants grown at $30^{\circ} \mathrm{C}$ had a decreased content of amylose in the endosperm starches, as compared with those grown at $25^{\circ} \mathrm{C}$ (cultivars: Nipponbare, Koshihikari and Hokuriku 93) and that the amylose content was affected by the environmental temperature from 5 to 15 days after anthesis, i.e. at an early stage of the grain filling period when the starch accumulation in endosperm cells is most active. Moreover, the higher environmental temperature seemed to increase the amount of long B chains and decrease that of short chains of amylopectin in the rice endosperm as compared with the lower environmental temperature groups, and the development stage when the fine structure of amylopectin was mainly affected by the environmental temperature was also $5 \sim 15$ days after anthesis and the same was the most effective as to the amylose con- tent in endosperm starch of rice.

To determine whether or not the effect of the environmental temperature on the fine structure of amylopectin is specific for the Koshihikari cultivar, further investigation was undertaken using waxy and nonwaxy nearisogenic lines of Taichung 65.

Starch granules were prepared from polished grains of rice plants grown under controlled temperature conditions. Amylose contents and the distribution of $\alpha-1,4$ chains of amylopectin were determined by gel filtration of isoamylase-debranched starches. Further details of the fine structure of waxy amylopectin were obtained by gel filtration of $\beta$ amylase-limit-dextrin, after debranching with isoamylase and pullulanase. Some physical and chemical properties of the starches were also examined by scanning electron microscopy (SEM), X-ray diffractometry and differ-

$\dagger$ Present address: Field Crop Div., Hokuriku National Agricultural Experiment Station, 1-2-1 Inada, Joetsu, Niigata 943-01, Japan.

†† To whom inquiries should be addressed. 
ential scanning calorimetry (DSC), together with evaluation of starch-granule susceptibility to amylase.

\section{MATERIALS AND METHODS}

Experimental plans for control of the environmental temperature of rice plants. Near-isogenic lines for the $w x$ locus were bred after seventeen backcrossings with Taichung 65 , nonwaxy cultivar, as a recurrent parent. The waxy line (group I) and its nonwaxy counterpart (group II) having spikelets which flowered within two days after heading were grown in a temperature-controlled growth chamber. The temperature conditions during the grain filling period are shown in Table I. Heat summation during the grain filling period was $1000^{\circ} \mathrm{C}$. The light intensity for the 12-hr-daylength was about 40,000 lux.

Enzymes. Crystalline Pseudomonas isoamylase (EC 3.2.1.68) and Aerobacter pullulanase (EC 3.2.1.41) were purchased from Hayashibara Biochemical Laboratories, Inc., Okayama, Japan. Pullulanase was purified by cyclohexaamylose-coupled Sepharose 6B affinity gel chromatography ${ }^{2)}$ and freed of $\alpha$-amylase. $\beta$-Amylase (EC 3.2.1.2), a product of Sigma Chemical Co., St. Louis, MO, U.S.A., was purified by the method of Marshall and Whelan ${ }^{3)}$ and by affinity gel chromatography, ${ }^{2)}$ and freed of $\alpha$-amylase and $\alpha$-glucosidase. A crude preparation of Rhizopus amagasakiens glucoamylase (EC 3.2.1.3) was kindly provided by Dr. Kiyoshi Kusai, Nagase Biochemical Co., Ltd., Fukuchiyama, Japan. Sources of pancreatin, glucose oxidase and peroxidase were reported previously. ${ }^{4)}$

Table I. Temperature Conditions for Rice Plants DURing the Grain Filling Period

\begin{tabular}{|c|c|c|c|}
\hline \multicolumn{2}{|c|}{ Group } & \multirow{2}{*}{\multicolumn{2}{|c|}{ Temparature condition* }} \\
\hline $\mathbf{I}$ & & & \\
\hline I- 1 & II- 1 & $25^{\circ} \mathrm{C} \quad 5$ days & $30^{\circ} \mathrm{C} 29$ days \\
\hline I- 2 & II- 2 & $25^{\circ} \mathrm{C} 10$ days & $30^{\circ} \mathrm{C} 25$ days \\
\hline I- 3 & II- 3 & $25^{\circ} \mathrm{C} 15$ days & $30^{\circ} \mathrm{C} 21$ days \\
\hline I- 4 & II- 4 & $25^{\circ} \mathrm{C} 20$ days & $30^{\circ} \mathrm{C} 17$ days \\
\hline I- 5 & II- 5 & $25^{\circ} \mathrm{C} 40$ days & \\
\hline I- 6 & II- 6 & $30^{\circ} \mathrm{C} \quad 5$ days & $25^{\circ} \mathrm{C} 34$ days \\
\hline I- 7 & II- 7 & $30^{\circ} \mathrm{C} 10$ days & $25^{\circ} \mathrm{C} 28$ days \\
\hline I- 8 & II- 8 & $30^{\circ} \mathrm{C} 15$ days & $25^{\circ} \mathrm{C} 22$ days \\
\hline I- 9 & II- 9 & $30^{\circ} \mathrm{C} 20$ days & $25^{\circ} \mathrm{C} \quad 16$ days \\
\hline $\mathrm{I}-10$ & II-10 & $30^{\circ} \mathrm{C} 34$ days & \\
\hline
\end{tabular}

* For example, group I-1 and II-1 were grown at $25^{\circ} \mathrm{C}$ for 5 days and then at $30^{\circ} \mathrm{C}$ for 29 days, and I- 6 and II- 6 , at $30^{\circ} \mathrm{C}$ for 5 days and then at $25^{\circ} \mathrm{C}$ for 34 days.
Preparation of rice starch granules. Starch granules were prepared from milled rice by the cold and dilute alkali method of Yamamoto et al. ${ }^{5,6)}$ as reported previously. ${ }^{1)}$

Measurement of iodine absorption spectra. Absorption curves of starch-iodine complexes were recorded with a Hitachi 220-type recording spectrophotometer with mixtures containing $1 \mathrm{mg}$ of starch, $2 \mathrm{mg}$ of iodine and $20 \mathrm{mg}$ of potassium iodide per $25 \mathrm{ml}^{7)}$

Debranching of starch with isoamylase and fractionation of debranched-materials. Rice starches were debranched with crystalline Pseudomonas isoamylase by the method of Ikawa et al. ${ }^{8)}$ Debranched materials were fractionated by gel filtration on columns of Toyopearl HW55SF and HW50SF (Toyosoda, Co., Ltd., Tokyo, Japan) connected in series. ${ }^{9)}$ The range of fractions I, II and III, and an intermediate fraction was divided according to the wavelengths of absorption maxima $\left(\lambda_{\max }\right)$ of absorption spectra of iodine-carbohydrate complexes in each tube, Fr. I, $\lambda_{\text {max }} \geqq 620 \mathrm{~nm}$, intermediate Fr., $620 \mathrm{~nm}>\lambda_{\text {max }} \geqq 600 \mathrm{~nm}$, Fr. II, $600 \mathrm{~nm}>\lambda_{\text {max }} \geqq 525 \mathrm{~nm}$, and Fr. III, $525 \mathrm{~nm}>\lambda_{\text {max }}$.

Preparation of amylopectin $\beta$-limit dextrin. Starch was digested with crystalline $\beta$-amylase by the method of Inouchi et al. ${ }^{10)}$ Starch (400 mg wet weight) was gelatinized in $1 \mathrm{~N}$ sodium hydroxide at $37^{\circ} \mathrm{C}$ for $2 \sim 3 \mathrm{hr}$, adjusted to $\mathrm{pH} 4.8$ with acetic acid, made up to $80 \mathrm{ml}$ with distilled water, and then incubated with 240 units of the purified crystalline $\beta$-amylase at $37^{\circ} \mathrm{C}$ for $24 \mathrm{hr}$. The digest was subsequently heated in boiling water for $5 \mathrm{~min}$ to inactivate the enzyme. The high molecular-weight materials were precipitated by the addition of 3 volumes of methanol. The precipitates were allowed to settle, and washed on a glass filter (G-4) with hot methanol to remove maltose and then with ethyl ether. The residue was dried at room temperature. One unit of $\beta$-amylase is defined as the amount of the enzyme releasing $1 \mu \mathrm{mol}$ maltose from soluble starch per min at $\mathrm{pH} 4.8$ and $37^{\circ} \mathrm{C}^{3)}$

Debranching of amylopectin $\beta$-limit dextrin. Amylopectin $\beta$-limit dextrin ( $30 \mathrm{mg}$ on a wet weight basis) was dissolved in $1 \mathrm{~N}$ sodium hydroxide at $37^{\circ} \mathrm{C}$ for $2 \sim 3 \mathrm{hr}$, and then neutralized with hydrochloric acid. The dissolved $\beta$ limit dextrin was incubated with 1475 units of isoamylase in $50 \mathrm{~mm}$ acetate buffer, $\mathrm{pH} 5.2$, at $40^{\circ} \mathrm{C}$ for $24 \mathrm{hr}$. The digest was subsequently heated in boiling water for $5 \mathrm{~min}$ to inactivate the enzyme. After cooling, the digest was incubated with 16 units of pullulanase at $\mathrm{pH} 5.2$ and $30^{\circ} \mathrm{C}$ for $24 \mathrm{hr}$. Under the conditions, $\beta$-limit dextrin of waxy maize starch was debranched completely. One unit of isoamylase is defined as the amount of the enzyme causing an increase in $A_{610 \mathrm{~nm}}$ of 0.1 for waxy rice starch at $\mathrm{pH} 3.5$ and $40^{\circ} \mathrm{C}$ for $1 \mathrm{hr},{ }^{11)}$ and one unit of pullulanase is defined as the amount of the enzyme releasing $1 \mu \mathrm{mol}$ maltotriose from pullulan in one min at $\mathrm{pH} 5.0$ and $30^{\circ} \mathrm{C} .^{12)}$ 
Fractionation of debranched $\beta$-limit dextrin. The debranched $\beta$-limit dextrin was dried in vacuo at $40^{\circ} \mathrm{C}$ and then dissolved in $67 \%$ aqueous dimethyl sulfoxide at $70^{\circ} \mathrm{C}$ for $3 \mathrm{hr}$. The solution $(1 \mathrm{ml})$ was put on a column $(2.2 \times$ $100 \mathrm{~cm}$ ) of Toyopearl HW50 superfine grade and eluted with distilled water under pressure $\left(1.0 \sim 2.0 \mathrm{~kg} / \mathrm{cm}^{2}\right)$ at $60^{\circ} \mathrm{C}$. Fractions $(2.0 \mathrm{ml})$ were collected every $6.5 \mathrm{~min}$. Fraction $\mathrm{I}_{\beta}$ (Fr. $\mathrm{I}_{\beta}$ ) was divided according to the wavelength of $\lambda_{\max }(\geqq 600 \mathrm{~nm})$ of absorption spectra of iodinecarbohydrate complexes in each tube. Fractions $\mathrm{II}_{\beta}$ and III $_{\beta}$ and IV $_{\beta}$ were divided according to the range of average chain lengths $(\overline{\mathrm{CL}})$. Namely, Fr. $\mathrm{II}_{\beta}, \overline{\mathrm{CL}} \geqq 17$, Fr. $\mathrm{III}_{\beta}, 17>\overline{\mathrm{CL}} \geqq 4$, and Fr. $\mathrm{IV}_{\beta}, 4>\overline{\mathrm{CL}}$ ( $c f$. Fig. 1 and Table IV and $\mathrm{V})$.

Analytical methods. The carbohydrate content was determined by the phenol-sulfuric acid method. ${ }^{13)}$ Reducing end groups were determined by the Park-Johnson method $^{14)}$ as modified by Hizukuri et al. ${ }^{15)}$ The average chain lengths $(\overline{\mathrm{CL}})$ were calculated from the amounts of carbohydrate and the number of reducing ends.

Other methods. The methods for determination of starch-granule susceptibility to amylases were reported previously. ${ }^{3)} \mathrm{X}$-Ray diffractometry was performed by the method of Hizukuri et al., ${ }^{16)}$ and the procedures for differential scanning calorimetry (DSC) and photopastegraphy were described elsewhere. ${ }^{17)}$

\section{RESULTS}

\section{Effect of environmental temperature on amylose content}

Table II summarizes some characteristics of isoamylase-debranched materials of endosperm starches of rice plants grown at different temperatures after pollination. Fraction I, of which the absorption maxima of the iodine-carbohydrate complexes are at longer wavelengths than $620 \mathrm{~nm}$, was regarded as amylose of the nonwaxy starch. Amylose was absent in the waxy endosperm starch of group $\mathrm{I}$, that is, it was composed of merely amylopectin. In group II (nonwaxy), groups II-1, II-8, II-9 and II-10 had endosperm starches with lower amylose contents (about 11 to $13 \%$ ) as compared with groups II-3, II-4, II-5 and II-6

Table II. Properties of Isoamylase-debranched Materials of Endosperm Starches from Rice Plants Grown at Different Temperatures during the Graing Filling Period after Pollination

\begin{tabular}{|c|c|c|c|c|c|c|c|}
\hline \multirow{2}{*}{ Groups } & \multirow{2}{*}{$\begin{array}{l}\lambda_{\max } \\
(\mathrm{nm})\end{array}$} & \multirow{2}{*}{$\begin{array}{l}\text { Blue value } \\
\text { (at } 680 \mathrm{~nm} \text { ) }\end{array}$} & \multicolumn{4}{|c|}{ Distribution of starch components $(\%)^{*}$} & \multirow{2}{*}{$\begin{array}{l}\text { Fr. III } \\
\text { Fr. II }\end{array}$} \\
\hline & & & Fr. I & Int. Fr. & Fr. II & Fr. III & \\
\hline I- 1 & 534 & 0.103 & 0 & 3.4 & 30.0 & 66.6 & 2.2 \\
\hline 2 & 529 & 0.092 & 0 & 3.5 & 28.6 & 67.9 & 2.4 \\
\hline 3 & 525 & 0.075 & 0 & 1.9 & 28.4 & 69.7 & 2.5 \\
\hline 4 & 524 & 0.076 & 0 & 2.2 & 26.7 & 71.1 & 2.7 \\
\hline 5 & 524 & 0.067 & 0 & 2.3 & 26.5 & 71.2 & 2.7 \\
\hline 6 & 525 & 0.066 & 0 & 3.3 & 26.7 & 70.0 & 2.6 \\
\hline 7 & 532 & 0.087 & 0 & 3.1 & 30.2 & 66.7 & 2.2 \\
\hline 8 & 534 & 0.102 & 0 & 4.3 & 29.6 & 66.1 & 2.2 \\
\hline 9 & 534 & 0.103 & 0 & 3.5 & 31.1 & 65.4 & 2.1 \\
\hline 10 & 534 & 0.102 & 0 & 4.2 & 30.2 & 65.7 & 2.1 \\
\hline II- 1 & 556 & 0.214 & 11.3 & 4.4 & 26.6 & 57.7 & 2.2 \\
\hline 2 & 561 & 0.247 & 15.8 & 3.7 & 23.5 & 57.0 & 2.5 \\
\hline 3 & 569 & 0.272 & 18.5 & 3.5 & 20.2 & 57.8 & 2.6 \\
\hline 4 & 570 & 0.280 & 19.6 & 3.1 & 20.9 & 56.4 & 2.7 \\
\hline 5 & 570 & 0.281 & 19.0 & 3.6 & 20.3 & 57.1 & 2.8 \\
\hline 6 & 569 & 0.282 & 19.2 & 4.4 & 21.1 & 55.3 & 2.6 \\
\hline 7 & 563 & 0.248 & 15.6 & 4.8 & 23.7 & 55.9 & 2.4 \\
\hline 8 & 556 & 0.226 & 12.5 & 4.4 & 26.2 & 56.9 & 2.2 \\
\hline 9 & 556 & 0.226 & 13.1 & 5.8 & 24.9 & 56.2 & 2.3 \\
\hline 10 & 556 & 0.223 & 12.3 & 4.7 & 26.3 & 56.7 & 2.2 \\
\hline
\end{tabular}

* Each fraction (Fr.) was divided according to the range of $\lambda_{\max }$ of iodine carbohydrate complexes as follows: Fr. I, $\lambda_{\max } \geqq 620 \mathrm{~nm}$, Intermediate Fr., $620 \mathrm{~nm}>\lambda_{\max } \geqq 600 \mathrm{~nm}$, Fr. II, $600 \mathrm{~nm}>\lambda_{\max } \geqq 525 \mathrm{~nm}$, and Fr. III, $525 \mathrm{~nm}>\lambda_{\max }$. 
(about 19 to $20 \%$ ). The amylose contents of groups II-2 and II-7 showed intermediate values (about 16\%).

Effect of environmental temperature on the fine structure of amylopectin

Figures $1 \mathrm{a}$ and $1 \mathrm{~b}$ show the gel-filtration profiles of total carbohydrate (solid lines) and reducing capacity (dotted lines) of the isoamylase-debranched waxy rice starches I-5 and I-10, respectively. Figures $1 \mathrm{c}$ and $1 \mathrm{~d}$ show those of the isoamylase-pullulanasedebranched materials of $\beta$-limit dextrins of waxy rice starches I-5 and I-10, respectively. Tables II and III show the percentages of total carbohydrate and those of reducing capacity of isoamylase-debranched materials, respectively. Tables IV and V show the percentages of total carbohydrate and those of reducing

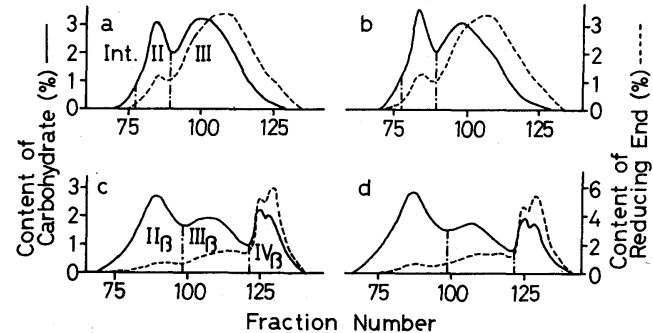

FIG. 1. Elution Patterns of Debranched Materials of Endosperm Starches and the $\beta$-Limit Dextrins of Rice (Cultivar: Taichung 65, Waxy) Grown at Different Temperatures after Pollination Following Enzymatic Debranching.

(a) and (b) Starches of groups I-5 and I-10 debranched by isoamylase. (c) and (d) $\beta$-limit dextrins of groups I-5 and I10 debranched by isoamylase and pullulanase, successively. For division of each fraction, see the legend to Table II for (a) and (b) and the legend to Table IV for (c) and (d). capacity of isoamylse-pullulanase-debranched materials of $\beta$-limit dextrins, respectively.

In Figs. 1a and $1 b$, Frs. II and III correspond to the linear unit-chains of amylopectin, because they showed peaks at about $\overline{C L} 40$ and 16, respectively, and appeared in debranched starches of both the waxy and nonwaxy types. The ratio of Fr. III to Fr. II was one of the characteristics of amylopectin. ${ }^{8)}$ The ratio in groups I-1, I-8, I-9 and I-10 was lower than that in groups I-3, I-4, I-5 and I-6. Namely, the amylopectin of groups I-1, I-8, I-9 and I-10 contained more long $\mathrm{B}$ chains than that of the other groups.

In Tables III and $\mathrm{V}$, the percentages of reducing capacity correspond to the numbers of chains. Fr. $\mathrm{I}_{\beta}$ was not contained in $\beta$-limit dextrins of waxy rice starches as shown in Figs. 1c and 1d and Tables IV and V. This is reasonable, since the waxy starches consisted of only amylopectin and Fr. $\mathrm{I}_{\beta}$ corresponded to the $\beta$-limit dextrin of amylose. The $\beta$ amylolysis of A chains of amylopectin terminates at the second or third $\alpha-1,4$-linkage before the 1,6-bond. ${ }^{18)}$ Therefore, maltose and maltotriose are released from the $\beta$-limit dextrin by debranching of stubs originating from A chains of amylopectin by isoamylase and pullulanase. Since Fr. $\mathrm{IV}_{\beta}$ consists of maltose and maltotriose, the percentage of reducing ends of Fr. $\mathrm{IV}_{\beta}$ represents the molar ratio of $\mathrm{A}$ chains in the original amylopectin component. The $\beta$-amylolysis of $\mathbf{B}$ chains of amylopectin terminates at the first or second $\alpha$-1,4-linkage before the 1,6-bond. ${ }^{18)}$ Debranching of stubs of $\beta$-limit dextrin originating from $\mathbf{B}$ chains of amylopectin by isoamylase and pullulanase

Table III. Percentages of Reducing End of Materials of Rice STARChES Debranched by IsOAMYlase*

\begin{tabular}{ccccccc}
\hline Groups & $\begin{array}{c}\text { Fr. I } \\
(\%)\end{array}$ & $\begin{array}{c}\text { Int. Fr. } \\
(\%)\end{array}$ & $\begin{array}{c}\text { Fr. II } \\
(\%)\end{array}$ & $\begin{array}{c}\text { Int. }+ \text { II } \\
(\%)\end{array}$ & $\begin{array}{c}\text { Fr. III } \\
(\%)\end{array}$ & $\begin{array}{c}\text { III/ } \\
\text { Int. + II }\end{array}$ \\
\hline I- 2 & 0 & 0.9 & 10.3 & 11.2 & 88.8 & 7.9 \\
I- 5 & 0 & 0.5 & 9.4 & 9.9 & 90.1 & 9.1 \\
I- 7 & 0 & 0.8 & 10.5 & 11.3 & 88.7 & 7.9 \\
I-10 & 0 & 1.0 & 11.2 & 12.2 & 87.8 & 7.2 \\
\hline
\end{tabular}

* See legend to Table II. 
Table IV. Percentages of Total CarboHYDRATE OF MATERIALS OF $\beta$-LIMIT DEXTRINS DEBRANCHED BY ISOAMYLASE and Pullulanase*

\begin{tabular}{ccccc}
\hline Groups & $\begin{array}{c}\text { Fr. I } \\
(\%)\end{array}$ & $\begin{array}{c}\text { Fr. II } \\
(\%)\end{array}$ & $\begin{array}{c}\text { Fr. III } \\
(\%)\end{array}$ & $\begin{array}{c}\text { Fr. IV } \\
(\%)\end{array}$ \\
\hline I- 2 & 0 & 42.3 & 36.0 & 21.7 \\
I- 5 & 0 & 41.1 & 37.3 & 21.6 \\
I- 7 & 0 & 45.5 & 33.8 & 20.7 \\
I-10 & 0 & 46.9 & 33.0 & 20.1 \\
\hline
\end{tabular}

* Fraction $\mathrm{I}_{\beta}$ (Fr. $\mathrm{I}_{\beta}$ ) was divided according to the wavelength of $\lambda_{\max }(\geqq 600 \mathrm{~nm})$ of absorption spectra of carbohydrate-iodine complexes in each tube.

Fractions $\mathrm{II}_{\beta}, \mathrm{III}_{\beta}$ and $\mathrm{IV}_{\beta}$ were divided according to the average chain lengths $(\overline{\mathrm{CL}})$. Namely, Fr. $\mathrm{II}_{\beta}, \overline{\mathrm{CL}} \geqq 17$, Fr. III $_{\beta}, 17>\overline{\mathrm{CL}} \geqq 4$, and Fr. $\mathrm{IV}_{\beta}, 4>\overline{\mathrm{CL}}$. results in malto-oligosaccharides of 4 glucose units or more. Frs. $\mathrm{II}_{\beta}$ and $\mathrm{III}_{\beta}$ correspond to the inner chains of the long $B$ and short $B$ chains of amylopectin, respectively. The percentages of reducing ends in $\mathrm{Fr} . \mathrm{II}_{\beta}$ for groups I-2, I-5, I-7 and I-10 were 10.7, 10.6, 11.7 and 12.5 , respectively (Table V). These values were in fairly good agreement with those of Fr. II plus Int. Fr. of the respective starches shown in Table III. The results indicated that Fr. $\mathrm{II}_{\beta}$ was produced by $\beta$-amylolysis of Fr. II and Int. Fr. in the starch. The short B chains of group I-10 were less than those of group I-5. Groups I-2 and I-7 showed intermediate values. The contents of A chain in all the 4 groups were similar to one another.

Table V. Percentages of Reducing End of Materials of $\beta$-Limit

Dextrins Debranched by Isoamylase and Pullulanase and Some Characteristics of $\beta$-Limit DeXtrins*

\begin{tabular}{cccccccc}
\hline Groups & $\begin{array}{c}\text { Fr. I } \\
(\%)\end{array}$ & $\begin{array}{c}\text { Fr. II } \\
(\%)\end{array}$ & $\begin{array}{c}\text { Fr. III } \\
(\%)\end{array}$ & $\begin{array}{c}\text { Fr. IV } \\
(\%)\end{array}$ & $\begin{array}{c}\text { Fr. III/ } \\
\text { Fr. II }\end{array}$ & A/B** & A+B/B** \\
\hline I- 2 & 0 & 10.7 & 29.0 & 60.3 & 2.7 & 1.5 & 2.5 \\
I- 5 & 0 & 10.6 & 30.1 & 59.3 & 2.9 & 1.5 & 2.5 \\
I- 7 & 0 & 11.7 & 28.8 & 59.5 & 2.5 & 1.5 & 2.5 \\
I-10 & 0 & 12.5 & 28.8 & 58.8 & 2.3 & 1.4 & 2.4 \\
\hline
\end{tabular}

* See the legend to Table IV.

** A: A chain, B: B chain. The A chain is linked to the rest of the molecule only through its reducing end-group; the $\mathrm{B}$ chain, in addition to being linked as an A chain is also substituted through the $\mathrm{C}_{6}$-hydroxyl in one or more of its constituent glucose units; the $\mathrm{C}$ chain carries the reducing end-group. ${ }^{19)}$

Table VI. DSC Characteristics of Endosperm Starches of Rice Plants Grown at Different Temperatures after Pollination*

\begin{tabular}{|c|c|c|c|c|c|c|c|c|}
\hline & \multicolumn{4}{|c|}{ Group I } & \multicolumn{4}{|c|}{ Group II } \\
\hline & $\begin{array}{c}T_{\mathrm{o}} \\
\left({ }^{\circ} \mathrm{C}\right)\end{array}$ & $\begin{array}{c}T_{\mathrm{p}} \\
\left({ }^{\circ} \mathrm{C}\right)\end{array}$ & $\begin{array}{c}T_{\mathrm{c}} \\
\left({ }^{\circ} \mathrm{C}\right)\end{array}$ & $\begin{array}{c}\Delta H \\
(\mathrm{cal} / \mathrm{g})\end{array}$ & $\begin{array}{c}T_{\mathrm{o}} \\
\left({ }^{\circ} \mathrm{C}\right)\end{array}$ & $\begin{array}{c}T_{\mathrm{p}} \\
\left({ }^{\circ} \mathrm{C}\right)\end{array}$ & $\begin{array}{c}T_{\mathrm{c}} \\
\left({ }^{\circ} \mathrm{C}\right)\end{array}$ & $\begin{array}{c}\Delta H \\
(\mathrm{cal} / \mathrm{g})\end{array}$ \\
\hline 1 & 65 & 72 & 82 & 3.0 & 64 & 70 & 84 & 3.5 \\
\hline 2 & 60 & 65 & 81 & 2.6 & 60 & - & 82 & 2.4 \\
\hline 3 & 59 & 64 & 80 & 2.5 & 59 & - & 81 & 2.7 \\
\hline 4 & 59 & 65 & 76 & 2.3 & 61 & 64,72 & 78 & 2.7 \\
\hline 5 & 59 & 64 & 77 & 2.3 & 60 & 66,73 & 80 & 2.4 \\
\hline 6 & 60 & 65 & 77 & 2.2 & 60 & 66 & 80 & 2.6 \\
\hline 7 & 65 & 70 & 79 & 2.5 & 64 & 70 & 85 & 3.0 \\
\hline 8 & 65 & 72 & 81 & 2.9 & 65 & 71 & 85 & 3.4 \\
\hline 9 & 66 & 71 & 81 & 2.9 & 65 & 72,78 & 85 & 3.6 \\
\hline 10 & 66 & 72 & 80 & 2.8 & 65 & 72 & 84 & 3.4 \\
\hline
\end{tabular}

* $T_{\mathrm{o}}$, onset, $T_{\mathrm{p}}$, peak, and $T_{\mathrm{c}}$, conclusion temperatures of gelatinization. $\Delta H$, heat of gelatinization. 


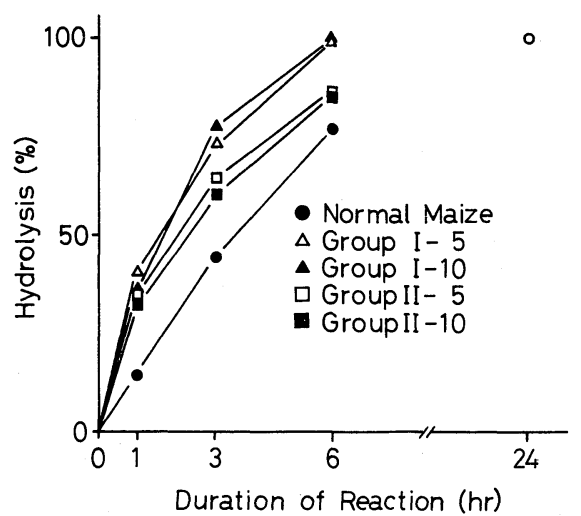

FIG. 2. Time Courses of Degradation of Endosperm Starch Granules of Normal Maize and Rice Plants Grown at Different Temperatures after Pollination by Glucoamylase of Rh. amagasakiens (Crude Preparation).

Effect of environmental temperature on other properties of starch

Table VI shows DSC characteristics of endosperm starches. Starch granules of groups I$1, \mathrm{I}-8, \mathrm{I}-9$ and I-10 showed higher onset $\left(T_{\mathrm{o}}\right)$ and conclusion $\left(T_{\mathrm{c}}\right)$ temperatures and greater heats of gelatinization $(\Delta H)$ on DSC than those of groups I-3, I-4, I-5 and I-6. Starch granules of group II showed similar DSC characteristics to those of starch granules of group I except that $T_{\mathrm{c}}$ and $\Delta H$ in group II were slightly lower than those in group I.

$\mathrm{X}$-Ray diffractograms of starches of groups I-5, I-10, II-5 and II-10 were of the type-A pattern which is typical of cereal starches.

Susceptibility to either $R h$. glucoamylase (Fig. 2) or pancreatin (data not shown) did not differ among these starch granules which were digested faster than starch granules of normal maize.

There were no differences among the groups in the shape, size or packing of starch granules in endosperm cells (data not shonw).

\section{DISCUSSION}

The higher environmental temperature $\left(30^{\circ} \mathrm{C}\right)$ decreased the amylose content in endosperm starches of Japanese rice cultivars in comparison with the lower one $\left(25^{\circ} \mathrm{C}\right)$. The amylose content in endosperm starch was af- fected by the environmental temperature from 5 to 15 days after pollination. ${ }^{1)}$ This was reconfirmed with the nonwaxy Japonica cultivar, Taichung 65, used in the present studies. Moreover, the results suggested that the fine structure of amylopectin was also affected by the environmental temperature. Namely, the higher environmental temperature increased the proportions of long B chains of amylopectin in the nonwaxy starches. ${ }^{1)}$ This was also confirmed by using waxy and nonwaxy nearisogenic lines of Taichung 65 (Table II). The higher environmental temperature increased the long $\mathbf{B}$ chains of amylopectin while decreasing mainly the short B chains and slightly the A chains as compared with the lower one (Fig. 1 and Tables IV and V). The development stage, when the fine structure of amylopectin was much affected by the environmental temperature, was 5 to 15 days after pollination and the same was the most effective for the production of amylose in the rice endosperm.

The pasting characteristics of starch granules were affected by the environmental temperature at which the granules were laid down regardless of the presence or absence of amylose in the starches. Namely, the onset and conclusion temperatures and heat of gelatinization on DSC of endosperm starch of rice plants grown at $30^{\circ} \mathrm{C}$ from 5 to 15 days after pollination were higher than those grown at $25^{\circ} \mathrm{C}$ (Table VI).

The range of environmental temperatures used in the experiments is optimum or suboptimum for the growth of rice plants. This may reflect the similar susceptibilities of starch granules to amylases and similar type-A X-ray diffractograms of starches.

The waxy and nonwaxy near-isogenic lines of Taichung 65 were used in this experiment, therefore, these two lines have the genetic background of Taichung 65, except that they carry either the waxy or nonwaxy allele at the $w x$ locus on chromosome 6 . The differences in the structures and properties of waxy and nonwaxy starches are taken as reflecting the difference in the allele. 
Acknowledgments. The authors are deeply indebted to Dr. H. Morishima, National Institute of Genetics, Mishima, Japan, for supplying the seeds of near-isogenic lines of Taichung 65 .

This investigation was supported in part by Grantsin-Aid from the Ministry of Education, Science and Culture of Japan, and the Nishin Seifun Foundation.

\section{REFERENCES}

1) M. Asaoka, K. Okuno, Y. Sugimoto, J. Kawakami and H. Fuwa, Stärke, 36, 189 (1984).

2) K. Iwaki and H. Fuwa, Agric. Biol. Chem., 45, 2683 (1981).

3) J. J. Marshall and W. J. Whelan, Anal. Biochem., 52, 642 (1973).

4) H. Fuwa, M. Nakajima, A. Hamada and D. V. Glover, Cereal Chem., 54, 230 (1977).

5) K. Yamamoto, S. Sawada and I. Onogaki, Denpun Kagaku, 20, 99 (1973).

6) K. Yamamoto, S. Sawada and I. Onogaki, Denpun Kagaku, 28, 241 (1981).

7) S. Fujimoto, T. Nagahama and M. Kanie, Nippon Nôgeikagaku Kaishi, 46, 577 (1972).

8) Y. Ikawa, D. V. Glover, Y. Sugimoto and H. Fuwa,
Stärke, 33, 9 (1981).

9) N. Inouchi, D. V. Glover, T. Takaya and H. Fuwa, Stärke, 35, 371 (1983).

10) N. Inouchi, D. V. Glover and H. Fuwa, unpublished data.

11) K. Yokobayashi, A. Misaki and T. Harada, Biochim. Biophys. Acta, 212, 458 (1970).

12) M. Abdullah and D. French, Arch. Biochem. Biophys., 137, 483 (1970).

13) M. Dubois, K. A. Gilles, J. K. Hamilton, P. A. Rebers and F. Smith, Anal. Chem., 28, 350 (1956).

14) J. Park and M. J. Johnson, J. Biol. Chem., 181, 149 (1949).

15) S. Hizukuri, Y. Takeda, M. Yasuda and A. Suzuki, Carbohydr. Res., 94, 205 (1981).

16) S. Hizukuri, Y. Takeda and J. Imamura, Nippon Nôgeikagaku Kaishi, 46, 119 (1972).

17) Y. Tomita, Y. Sugimoto, S. Sakamoto and H. Fuwa, J. Nutr. Sci. Vitaminol., 27, 471 (1981).

18) D. French, "Control of Glycogen Metabolism," ed. by W. J. Whelan and M. P. Cameron, J. A. Churchill, Ltd., London, 1964, pp. 12 13.

19) S. Peat, W. J. Whelan and G. J. Thomas, J. Chem. Soc., 4546 (1952). 